\title{
Is Rote Learning of Number Concepts 'Inherently Rotten' or Is It Just a Blame and Shame Game that Vitiates Principles of Natural Progression?
}

\author{
Michael Kainose Mhlolo (Dr) \\ Faculty of Humanities, Central University of Technology - Free State \\ mmhlolo@cut.ac.za
}

\section{Doi:10.5901/mjss.2014.v5n27p1581}

\begin{abstract}
This paper questions the validity of the foundational premise of the 'problem-solving movement' following a perennial dichotomization of the 'old' and 'new' math curricula globally. Essentially, the substance of the controversies that places the 'problem solving movement' and the 'back-to-basics movement' on the opposite ends of the 'battle-fields' is the view within the former that rote learning is unimportant or counterproductive as it does not enhance the development of application skills of critical thinking, logical analysis, and creative problem-solving. The paper then uses Tall's framework to show how counting is foundational to number concept formation and how rote learning is a necessary first step in this counting process. I then argue that the suggestion that critical thinking could be developed without the lower level concepts is possibly founded on a flawed premise. Globally, there is a current wave of back-to-basics across mathematics curricula. However it would appear in the South African curricula for Foundation Phase Grade $R-3$, rote learning is still not valued despite going back-to-basics. This suggests a continued dichotomization of the old and new approaches which does not seem to be beneficial to learners who tend to end up with neither the problem solving skills nor the basic foundational knowledge. The paper recommends that we develop teaching methodology for mathematics and other subjects that incorporates rote learning in an effective way so that knowledge is better conveyed and represented in the minds of students.
\end{abstract}

Keywords: rote learning, number concepts, encapsulation, South Africa

\section{Introduction}

Globally, there is a current wave of back-to-basics across mathematics curricula where the so called 'old school' approaches are now being incorporated back into the 'new'. This is not the first time that mathematics curricula reforms have gone back-to-basics. In fact in a paper entitled "The Math Wars", Schoenfeld (2004), captured these ping pong movements between the old and the new curricula through a distillation of 100 years of curriculum trends and controversies in mathematics instruction. More recently Wright (2012), wrote about these never ending debates showing many parallels between how the school mathematics curriculum has evolved in England and in the United States, typified by a shift in one direction, within the dominance of one educational ideology, followed by a shift in a different or opposite direction, with the ascendancy of a conflicting ideology. In the midst of these debates stretching over a century, the old has become the new and vice versa several times such that the terms 'old curriculum' and 'new curriculum' have since lost their traditional meanings denoting time and have since acquired new meanings denoting these conflicting ideologies to mathematics teaching and learning.

In their newly acquired meanings, the term new curriculum is now generally discussed with reference to a 'problem-solving movement' whose ideology aligns with the constructivist agenda with its tenets of learner-centredness, critical thinking, logical analysis and such other ' $21^{\text {st }}$ century skills'. On the other hand the term old curriculum is now generally associated with this 'back-to-basics movement' where we also find a plethora of derogative terms that have been used by its critics to refer to some form of rote learning. A few of these derogatory terms include parrot fashion, regurgitation, cramming, mugging, surface/ superficial learning, memorization, recall, drilling, algorithmic and procedural learning. In this paper the terms old and new curriculum will be used with reference to these newly acquired meanings.

Essentially, the substance of the controversies that places the 'problem solving movement' and the 'back-to-basics movement' on the opposite ends of the 'battle-fields' is the view within the former that rote learning is unimportant or counterproductive as it does not enhance the development of application skills of critical thinking, logical analysis, and creative problem-solving. On the other hand, the 'back-to-basics movement' argues that critical thinking and problem solving skills are based on well-learnt hierarchically lower-level concepts which in some cases are only developed through rote learning. Expecting learners to have critical thinking skills without these lower-level concepts is like depriving 
them of the tools they need for fluid, competent performance which then forces the students towards those very same aspects of rote memory, such as counting fingers, that the problem solving movement is trying to despise. Hence the suggestion that critical thinking could be developed without the lower level concepts is possibly founded on a flawed premise.

A common concern raised about the math wars is that like all wars, they have casualties - our children, who do not receive the kind of robust mathematics education they should (Egan, 2004). This concern arises from observations made that there are no substantial numbers of students who have gone through such "problem-solving" reform curricula and emerged demonstrably competent in problem solving. In fact Egan (2004) argues that learner-centred theory in one form or the other has been implemented in American schools and elsewhere since the early $20^{\text {th }}$ century. Each attempt has persistently failed, and after each failed attempt the foundational belief and its tenets are re-applied but clothed in a "new" form with new terminology. Based on an analysis of results from decades of trials of problem-based instruction; Schoenfeld (2004), argued that the problem solving movement was superficial and the approach was a travesty of justice as it denied learners from less privileged communities access to quality mathematics education. Not only did the approach fail to produce the expected outcomes with students showing little ability in problem solving but ironically performance on the 'basics' had not improved either. This persistent failure suggests that either the ways of implementing problem-solving approaches were wrong or that the foundational belief is wrong and does not correspond to reality. Due to this conceptual mess that dichotomizes the old and the new; Narayan (2009), posits that it could be just this same sense of urgency to give knowledge and critical thinking ability to students, that ironically could be denying the students the abilities that they so desire. It is in this context that one of the goals of this paper is to analyse the extent to which rote learning could possibly be a pre-requisite for concept formation in mathematics.

\subsection{Objectives of this paper}

This theoretical paper questions the validity of the foundational premise of the 'problem-solving movement' view that encourages development of critical thinking skills while discouraging rote learning. Critical analysis of the premises undergirding a theory is of utmost importance. As Archer pointed out:

...we must keep our attention fixed on the premises, not be content to enjoy the rhetorical unrolling of the conclusions .... It is for the reader to see how far errors in the premises vitiate the conclusions (1928:7).

A theory's validity lies not only in its logical coherence, but its truth, its rightness or wrongness, lies in the foundational beliefs and premises, whether they accord with the reality that the theory presumes to describe and predict. A theory with wrong premises can never be successfully implemented.

This paper is steered through its course by the following questions:

$>$ What are some of the basic and critical concepts in mathematics?

$>$ How do these concepts develop?

$>$ What role if any does rote learning play in preparing learners for such concept formation in mathematics?

\section{Why this Interest}

In South Africa Vithal \& Volmink (2005), argue that many of the present curriculum reforms may be characterized as waves of change borrowed from the west each bringing in a tide of buzz words followed by uncritical replication. For example, in the United States, the revised version of Standards (NCTM, 2000) outlined a balanced view of teaching for understanding that pays adequate attention to both skills and problem solving (Wright, 2012). A similar shift is observed in the United Kingdom where in January, 2011, the new Conservative and Liberal Democratic coalition government announced a review of the curriculum with greater emphasis on facts and figures and academic rigour (Garner, 2011). In South Africa the latest Curriculum and Assessment Policy Statement (CAPS) Mathematics across Grades R-12 gives expression of the knowledge, skills and values worth learning in the schools. "This curriculum aims to ensure that children acquire and apply knowledge and skills in ways that are meaningful to their own lives" (Department of Basic Education, 2012:4). The common buzz words that emerge across these latest global visions on curriculum design point to the need in mathematics teaching to make stronger connections between 'conceptual understanding' and 'factual knowledge', with a renewed emphasis on the latter (Wright, 2012). In the South African CAPS document for Intermediate Phase grade 4 6 evidence of this renewed emphasis on factual knowledge can be seen in the way time is now allocated to mathematics teaching and learning. The document stipulates that teachers should spend 10 minutes daily on mental mathematics 
giving a total of 8 hours of mental mathematics out of the total 60 hours (i.e. 13\%) allocated to the subject per term. Generally mental mathematics activities focus on factual knowledge and this is clear from how the activities are prescribed in the documents.

Prior to these latest global developments the predominant view that shaped curriculum design was the emphasis on application skills of critical thinking, logical analysis, and creative problem-solving; skills which 'rote learning did not help learners to develop' - so the critics of the 'back-to-basics movement' argued. Lamenting the lack of analysis before adopting foreign curricula, Vithal \& Volmink (2005), posit that the 'New-Math' movement, that has shaped curriculum development in the Western countries, has also left its mark on mathematics curriculum in South Africa, albeit in the form of curriculum changes that have followed uncritically the loudest fad from the source. Rote learning is one such 'buzz' phrase which was central to the debates that swayed both policy-makers and practitioners in education towards the 'more appealing' learner-centredness and its tenets of critical thinking and problem-solving. Now that curricula globally have gone back-to-basics, has this negative view to rote learning changed or are we seeing yet a re-application of the problemsolving approaches clothed in the 'new' form with new terminology 'back-to-basics'? With specific reference to the Intermediate Phase Grades $4-6$; the current CAPS in South Africa is explicit in that it espouses 'active and critical learning' where learners are expected to develop an active and critical approach to learning, rather than rote and uncritical learning of given truths (Department of Basic Education, 2012). The phrase 'rather than rote' suggests that rote learning is still not valued despite the curriculum having gone back-to-basics and re-emphasizing factual knowledge.

Egan (2001) would have asked; 'What have we been getting wrong from the beginning' [by suggesting that rote learning was unimportant? (my emphasis)]. I add to that question; 'Are we getting it right this time or do we remain in the catastrophe of continuous choking in a conceptual mess?' Although Egan (2004) used a metaphor of choking in a conceptual mess with specific reference to the American Education system, her observation resonates with what is happening in South Africa. Egan laments:

Here we are with massive financial and technical resources at hand to educate our children, but we are in a conceptual mess, and the result is ignorance and waste of life in catastrophic proportion (2001:13).

This paper argues that South Africa (and possibly other countries) could be in this conceptual mess as the country is comparatively well resourced yet performance at all levels of the schooling continues to be described in terms of a crisis (Venkat \& Askew, 2012). Commenting on this crisis across the levels Fleisch (2008) pointed out that primary school learners had limited proficiency with basic operations such as addition, multiplication and division. Similarly at the secondary level, a significant observation made was that many learners used their fingers or 'sticks' on the page to solve addition and multiplication problems (Schollar 2008). Commenting on the need to revisit the basics, Egan (2004), suggests that such failure indicates a possible error in the current learner-centred interpretation of teaching and organizing systematic learning. Brodie \& Pournara (2005), therefore suggest that the next important steps, particularly for research and teacher education, are to critique, adapt, modify and complete these visions (problem solving, learnercentredness) in ways which enable teachers and learners to achieve new ways of working in their classrooms. It is in this context that this paper analyses concept formation in mathematics and the extent to which role rote learning assists such processes. The two key questions in this regard are: (1) what exactly must be known by learners of mathematics and (2) how exactly must that which must be known be learned?

\section{Foundational and Critical Concepts in Mathematics}

As an entry point into the identification of the basic and critical concepts in mathematics this paper borrows a question that was raised by members of a task team which was charged with the responsibility of identifying Curriculum Focal Points for the National Council of Teachers of Mathematics (NCTM, 2006). In developing these major instructional goals a question raised by the members was; 'What characteristics qualify a concept or topic to be a curriculum focal point?' In response to this question consensus was reached that a focal point had to pass three rigorous tests:

- Is it mathematically important, both for further study in mathematics and for use in applications in and outside of school?

- Does it fit with what is known about learning mathematics?

- Does it connect logically with the mathematics in earlier and later grade levels?

A number of core concepts in mathematics were then identified as meeting these criteria and were therefore described as indispensable towards the development of problem solving, reasoning and critical thinking skills, which are important to all mathematical learning. These core concepts were then put into some hierarchical structure and weighted to show their relative importance. This was premised on the view that mathematics by its nature is a structured subject and that very same structure dictates that certain topics must be taught before others, and, in most cases, must be 
mastered before any understanding of the next topic can even be hoped for.

Although Fig. 1 is extracted from the South African Mathematics Curriculum for Foundation Phase (Grades R - 3), it depicts what could be described as a replica of the American version of the 'focal points'. Many other mathematics curricula globally (Hong Kong, Singapore, Korea) have similar topics, sequencing and emphasis (Ginsburg, Leinwand \& Decker, 2009). In fact the South African CAPS documents refer to them as focus content area confirming the impact of the American version of the 'focal points' on curriculum design globally.

\begin{tabular}{|l|c|c|c|}
\hline WEIGHTING OF CONTENT AREAS & Grade & Grade 2 & Grade 3 \\
\hline Content Area & $65 \%$ & $60 \%$ & $58 \%$ \\
\hline Numbers, Operations and Relationships* & $10 \%$ & $10 \%$ & $10 \%$ \\
\hline Pattems, Functions and Algebra & $11 \%$ & $13 \%$ & $13 \%$ \\
\hline Space and Shape (Geometry) & $9 \%$ & $12 \%$ & $14 \%$ \\
\hline Measurement & $5 \%$ & $5 \%$ & $5 \%$ \\
\hline Data Handling (Statistics) & $100 \%$ & $100 \%$ & $\mathbf{1 0 0} \%$ \\
\hline
\end{tabular}

Figure 1: Weighting of content areas (Department of Basic Education, 2012)

From the way the content areas are weighted, what stands out clearly from the percentages is the disproportionate emphasis that is placed on number and number operations. An asterisk is further placed against this topic followed by a statement;

In grade $R-3$, it is important that the area of Numbers, Operations and Relationships is the main focus of Mathematics. Learners need to exit Foundation Phase with a secure number sense and operational fluency..... Most of the work on patterns should focus on number patterns to consolidate learners' number ability further.

This double emphasis suggests the importance that is placed on number to the learning of mathematics and this is also reflected in the other curricula across the grades. Similarly, the Hong Kong standards for grades 1-3 devote approximately half the targeted time to numbers and almost all the time remaining to geometry and measurement (Ginsburg, Leinwand \& Decker, 2009). In fact according to the National Research Council (2009), mathematics experiences in early childhood settings should concentrate on (1) number (which includes whole number, operations, and relations) and (2) geometry, spatial relations and measurement, with more mathematics learning devoted to number than to other topics. Hence according to Rips, Bloomfield \& Asmuth (2008), there seems to be no serious disagreement that numbers are the foundation of mathematics.

So having established number operations and relationships as what must be known by learners of mathematics I was then interested to answer the next question of how number concepts must be known. When planning for teaching and learning activities, the area of number has usually been sub-divided into subcategories which include whole numbers, fractions, decimals, percentages and the four number operations i.e. addition, subtraction, multiplication and division. In terms of number concept formation, (Gray \& Tall 1994; Tall 2007) collapse these subcategories into two broad but complimentary categories i.e. process and concept; arguing that a symbol such as "3" evokes both the counting process "one, two, three" and the cardinality of the number " 3 " itself. They then describe number concepts as elementary procepts; a term they built by combining the two forms of number i.e. process and concept.

\subsection{Procedures first or concepts first}

Given that number can be viewed as a procept, I was then interested to understand which of these two 'process' or 'concept' is foundational to number concept formation. Although there have been mixed views regarding the order in which learners develop procedures and concepts, researchers such as (Sfard 1991; Hiebert \& Lefevre 1986) made explicit predictions, claiming a distinct ordering of the process and object conceptions (operational and structural conceptions in Sfard's terms). Sfard suggested that the process came first, followed by the object:

We have good reasons to expect that in the process of concept formation, operational conceptions would precede the 
structural (1991:10).

Similarly, Hiebert \& Lefevre argued that:

\begin{abstract}
....although it is possible to consider procedures without concepts, it is not so easy to imagine conceptual knowledge that is not linked to some procedures. This is due, in part, to the fact that procedures translate conceptual knowledge into something observable. Without procedures to access and act on the knowledge we would not know it was there (1986:9).
\end{abstract}

This notion that there are stages in mathematical development and that learners typically go through a procedurally oriented phase before they can effectively integrate their conceptual knowledge is also put forward by (Grey \& Tall, 1994; Tall, 2007). Although Gray \& Tall later proposed other ways in which the complicated details of a particular situation (e.g. geometry) could be compressed to give a rich simplicity in mathematics; Tall (2007), still maintained that the proceptualsymbolic world of number is initially an action based world starting with actions on physical objects. By symbolizing the actions and using the symbols as manipulable objects the system changes focus to the symbols themselves as procepts. Reflections on the relationships then leads to building connections between the properties of these procepts enabling us to describe new concepts such as 'sum', 'product', 'difference', 'quotient', 'prime number', and so on. This shift of attention from action to effect proved to be an embodied form of compression that corresponded naturally to symbolic compression from procedure to process and on to concept (Tall, 2007).

Given that there are many number processes and procedures a question that could be asked is; "Which one of these procedures is foundational to the learning of number concepts?" The National Council of Teachers of Mathematics NCTM (2006:11) suggests that 'counting is the first and most basic mathematical algorithm.' Children develop an understanding of the meanings of whole numbers and recognize the number of objects in small groups by counting. They understand that number words refer to quantity. They use one-to-one correspondence to solve problems by matching sets and comparing number amounts and in counting objects to 10 and beyond. They understand that the last word that they state in counting tells "how many", they count to determine number amounts and compare quantities using language such as 'more than' and 'less than', and they order sets by the number of objects in them.

There seems to be a general consensus that learning to count is a child's very first step into mathematics, and constitutes the most fundamental idea of that discipline (Schoenfeld, 2004). According to Rips, Bloomfield \& Asmuth (2008), many theorists believe that once children have learned language, or at least language based counting, they are in a position to attain true concepts of natural numbers and that they are able to perform tasks such as enumerating the items in an array or carrying out simple commands (e.g. Give me six balloons.) Cognitive research on the development of number concepts rests on the idea that such concepts depend on enumerating objects. According to Baroody \& Wilkins (1999), it could be argued that the construction of counting concepts and skills is the single most important element in pre-schoolers' mathematical development as they provide a basis for the development of number and arithmetic concepts and skills. Not only do Gray \& Tall (1994), posit that at the foundation of arithmetic is the concept of number which has its origins in the process of counting but in their long journey of studying development of number concepts they have shown how the critical number operations like addition, subtraction, multiplication and division are just different forms of both rudimentary and advanced counting. This suggests that mathematics could be viewed as a generalization of these counting procedures (Wilson, 2009) and in order to make a strong case for counting I was interested in further understanding how all the other procedures link with counting.

\title{
3.2 Hierarchical levels of counting
}

According to Gray \& Tall (1994), number awareness involves both the process of counting and the product of the process. At first, oral counting may be nothing more than a "sing-song" - a pattern of sounds (one, two, three, four....) uttered without any apparent number conceptualization but the sequence of those words has to be memorized as it makes the solid foundation upon which concepts of number are built.

In time children then extend this skill of putting number words into a sequence to the task of generating one-to-one correspondence. That way the sequence of number words become part of a procedure to point at successive elements calling out each number in turn until the last word is identified as the number of elements in a collection (object counting and cardinality). This object counting (four cups, four chairs, four dogs, four children) leads eventually to number invariance which might be termed the "fourness" of four. Later the children also learn how to use the counting sequence to create their own collections (counting out sets) and to compare the number in successively larger or smaller collections (bigger than or smaller than). Later on the process of counting develops further enabling the child to identify the number 
of elements in more than one collection e.g. $3+5=8$ which suggests that the child has to count elements in one collection (3) then either 'count on' (5) or 'count all' (3 and 5) which results in a new procept of 'sum'.

According to Gray \& Tall (1994), this proceptual encapsulation occurs at various stages throughout mathematics: counting on, counting all or repeated counting becoming addition (sum), skip-counting, repeated addition becoming multiplication (product), counting backwards or reversing addition to give subtraction and so on. So, as proceptual thinking grows in conceptual richness, procepts can be manipulated as simple symbols at a higher level to perform computations. Thus counting, addition, multiplication are seen as operating on the same procept which can be decomposed into richer processes for calculation, giving what are usually considered by mathematics educators as complex hierarchy of relationships (Fig. 2)

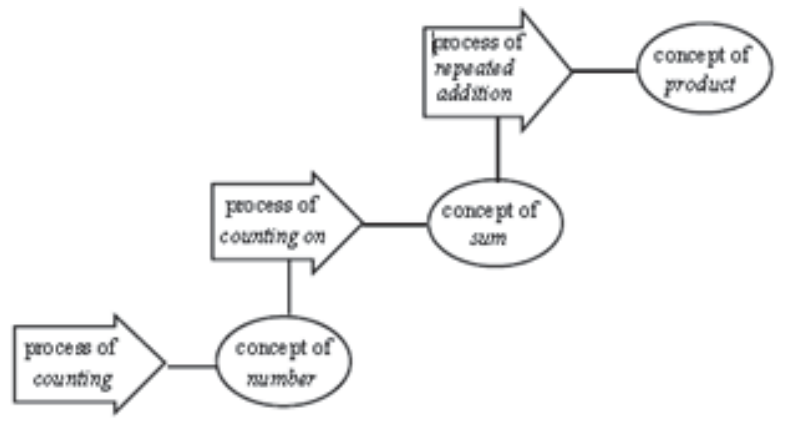

Figure 2: Higher order encapsulations (Gray \& Tall, 1994)

In fact Wilson, (2009) confirm this position as they argue that addition, subtraction, multiplication and division of whole numbers represent the basic operations of mathematics and much of mathematics is a generalization of these operations and rests on an understanding of these procedures. A proceptual view which amalgamates process and concept through the use of the same notation therefore collapses the hierarchy into a single level in which arithmetic operations (processes) act on numbers (procepts) as shown in Fig. 3.

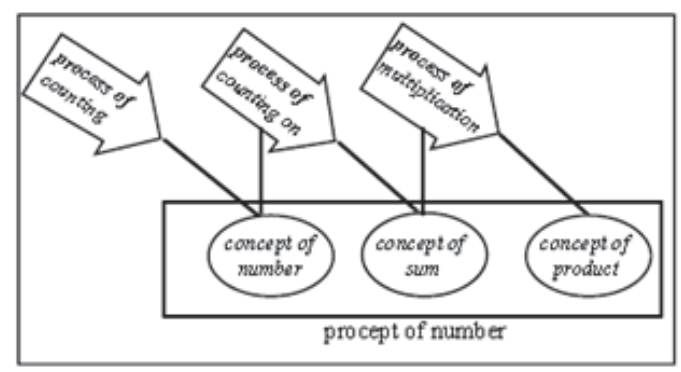

Figure 3: Collapse of hierarchy into operations on numbers (Gray \& Tall, 1994)

Gray and Tall (1994) hypothesized that this is the development by which the more able thinker develops a flexible relational understanding in mathematics, which is seen as a meaningful relationship between notions at the same level, whilst the less able are faced with a hierarchical ladder which is more difficult to climb.

Having identified number as an area which is foundational to and critical for mathematical learning; and that the concept of number has its origins in the process of counting; and that number operations (addition multiplication, subtraction and division) could be viewed as different forms of both rudimentary and advanced counting; I now want to focus a bit more on how children learn to count. This focus is critical in order to answer the question; 'What role if any does rote learning play in preparing learners for such concept formation (like counting) in mathematics?'

\subsection{How do children learn to count?}

Generally Rips et al.,(2008) have argued that children's quantitative concepts are not innate since there is no evidence from studies of infants that they possess concepts of number and many definitional properties of the natural numbers are 
unknown to them. So children have to undergo conceptual change in order for their quantitative ideas to qualify as true number representations. So Rips et al. developed two terms 'simple' counting and 'advanced' counting (enumeration) to enable them to describe children's development of number concepts. Their view is that children's entry point is through 'simple' counting which consists of just reciting the number sequence to some fixed numeral, for example, 'ten' or 'one hundred'. So at first recitation is focused on mastery of the order or sequence in which the number words are arranged because learners have a fragmentary knowledge of number at this stage. This recitation of the number word sequence allows children to form a schema for the numbers that specifies the number structure as a countably infinite sequence and once this schema is in place, they can then use it to reorganize and to extend their fragmentary knowledge. So enumerating which only comes later (advanced counting) typically involves pairing verbal numerals with objects to reach a determinable total or cardinality of the set of objects.

Similarly Wynn (1992), argues from a 'different contexts theory' which also posits that children sequentially acquire number word meanings through three different contexts from the sequence, through the counting to the cardinal contexts of number. According to Wynn,

...sequence meanings occur in contexts in which the number words are recited in sequence, but not used to count actual items or to refer to the numerosity of some set of items. The meaning of number word in this context is that it comprises part of this sequence; the words have no referents. The evidence for such a stage is that in children's earliest productions of the number word list, they treat the words as an unbreakable string, a sequence of sounds with no intrinsic meaning, recited by rote (1992:223 - 224)

The number words later take on a counting meaning when used as tags for each one of the items in a group (oneto-one correspondence). In describing what learners do when faced with the task of learning which word goes with which tag Wynn claims that this requires the learners to memorize the order of the number words first then assign a number word in the word list to each item by labelling them one, two three etc. Wynn therefore argues that children first learn counting through rote reciting of number word sequences and that the development of the meanings of the number words is a central part of their understanding of the counting system. In this theory, a number word is later used in the cardinal context when it describes the cardinality or numerosity of a set of objects. This trajectory suggests that the different number contexts of sequence, counting, and then cardinal; gradually become interrelated to give a child a more comprehensive number sense.

These views resonate with Narayan's (2009), argument that when a child starts with a new field of knowledge (such as number) of which one does not have any previous experience; learning is very difficult because the concept of number has no meaning and the child has nothing to associate any new idea with. Thus rote learning of the number words in a sequence is the only plausible approach at this stage as it corresponds to fixing up single entities in the mind on which to build the semantic nets of number. Until this skeleton network is established, nothing can be added to it as further association e.g. one-to-one correspondence leading to cardinality of number. Establishing skeleton network through any other method is not quite practical (Narayan, 2009). Similarly, Long (2005), posits that children learn to count through nursery rhymes and recognize the symbols and the sequence or order in which they come before they develop the understanding of cardinal number.

Although this view of rote learning is exemplified as being a necessary first step in number concept formation, Berger (2006), extends it to the learning of any other new mathematical object. According to Berger the issue of how an individual makes personal meaning of a 'new' mathematical object is a fundamental issue in mathematics education. Her argument revolves around Vygotsky's idea of the functional use of a sign. Vygotsky (1986), regards a word [such as three] as embodying a concept - the threeness of 3 . He postulates that the child used the new word 3 for communication purposes before that child has a fully developed understanding of that word and in that way this usage precedes an understanding of the mathematical objects signified by the mathematical sign 3. According to Vygotsky:

Words take over the function of concepts and may serve as means of communication long before they reach the level of concepts characteristic of fully developed thought (1986:101).

In terms of this notion, the learner's use of the mathematical signs (such as one, two, three....) in activity and communication with adults is a necessary first step in the appropriation of mathematical meaning. The point Berger (2006), makes is that by using various signs in mathematical activities, students are able to engage with the mathematical object on first contact, albeit in an idiosyncratic fashion. In this way the student gains a point of entry into mathematical activities with the object before he 'knows' that object. The movement from this confusion or objectively incoherent usage of mathematical signs or words to a usage which is both personally satisfying and mathematically acceptable is through imitation of the signs and words - which is basically rote-learning. According to Berger, understanding the extreme case 
of a mathematical object introduced through a definition provides a window into what is happening when a learner encounters a new mathematical object, no matter the academic level and no matter that it may be introduced through exemplars and/or with diagrams as is common practice in many South African high schools.

\section{Discussion}

This paper has shown how generally the math wars are waged from a polarized 'memorized' and 'understood' continuum where the predominant view has been that superficial/rote/memorization of concepts/procedures is "bad" while deep understanding of both is "good". While there might be fewer disputes on the view that deep understanding of either procedures or concepts is good, the 'rote is bad' view has been the subject of contestation before and is the object of this paper. So in this section I now want to answer the question: What are some of the premises upon which the 'rote is bad' view is built and what are the possible errors in the premises that seem to vitiate the conclusions?

The first premise is that rote learning is habitual repetition and devoid of conceptual understanding. In this sense rote learning is defined as a style of learning in which pupils seek only to retain and later to recall some information, result or process, without necessarily making cognitive connections between the new learning and their existing network of understanding (Narayan, 2009). So by definition, rote learning eschews comprehension with the implication that rote learning does not create a building block on which knowledge can be built, and does not provide a skill or knowledge that can be connected with any other skill or knowledge.

That rote learning is devoid of conceptual understanding is true but that it does not provide connections with any other knowledge could be flawed. It suggests that once students are taught through rote, they do not reflect on that experience later. Psychologists refer to this type of life view as an episodic grasp of reality (Feuerstein, Rand, Hoffman, \& Miller, 1980). It captures only an episode and not the whole process of learning. A defining condition of being human is that we have to understand the meaning of our experiences and we accomplish this through reflection. To reflect, we must act upon and process the information we have been exposed to whether by rote or some other strategy, synthesizing and evaluating the data. In the end, reflecting also means applying what we've learned to contexts beyond the original situations in which we learned something. In this case rote learning is only bad if it does not eventually result in deeper understanding i.e. endpoint of acquisition in Star's (2005) description. Hence Rips et al., (2008) suggest that it is not rote learning that is bad but bit is accounting for the transition between these preliminary representations and mature ones that creates the theoretical gap or what Egan (2001), referred to as the conceptual mess.

This paper has just shown how learners initially learn counting through rote; and how they should then reflect on the sequences of number words and apply it to enumerating (one-to-one correspondence), leading to cardinality of sets, adding, multiplying and other more complex processes. This shows the critical role counting plays in the development of number concepts and how rote learning is a necessary first step in the appropriation of mathematical meaning thereof. Berger (2006), extends this to the acquisition of other mathematical content and suggests this is what is happening when a learner encounters a new mathematical object, no matter the topic/content or the academic level. She argued that through imitation of signs and symbols (rote learning) a student gains a point of entry into mathematical activities with the object before he 'knows' that object. It was only through continued use of the word with the adults that learners reflect on and later refine their sense making.

A second premise is that rote learning focuses on memorization which stifles originality - so the charge runs. From this perspective, rote learning contrasts with meaningful learning of mathematics because it involves the memorization of a great number of individual facts and routines, such as addition facts, multiplication tables and algorithms for calculations. However, higher order thinking skills, such as independent, critical thinking and problem-solving, are always conjoined to relevant, domain-specific information, and therefore such skills cannot be gained and subsequently exercised without having committed the associated information to memory (Hirsch, 1996). According to Weeks, (1988) people who have had an education opposed to memorization have great trouble in committing to memory the knowledge that is basic to and essential for their chosen professions. Most if not all, professions require their practitioners to have a mass of detailed information stored in their memory. So the denigration of memorization is in fact a denigration of knowledge, and ultimately a defeat of the educational ideal of stimulating problem-solving and independent, critical thinking. As Hirsch points out;

Independent-mindedness is always predicated on relevant knowledge: one cannot think critically unless one has a lot of knowledge of the issue at hand. Critical thinking is not merely giving one's opinion (1996:247).

Similarly, according to Phillips:

In-depth understanding requires detailed knowledge of the facts within a domain. The key attribute of expertise is a 
detailed and organized understanding of the important facts within a specific domain. Education needs to provide children with sufficient mastery of the details of particular subject matters so that they have a foundation for further exploration within those domains (2005:589).

In fact common sense tells one that the person who can think critically and who can solve problems is, without exception, one who has sufficient knowledge of the relevant issue or problem - which he/she has committed to memory (Horn, 2009). Kirschner, Sweller \& Clark acknowledge this as they argue that;

\begin{abstract}
...expert problem solvers derive their skill by drawing on the extensive experience stored in their long-term memory and then quickly select and apply the best procedures for solving problems [...] We are skilful in an area because our longterm memory contains huge amounts of information concerning the area. That information permits us to quickly recognize the characteristics of a situation and indicates to us, often unconsciously, what to do and when to do it (2006:76).
\end{abstract}

Research has shown that in mathematics, one who has memorized the multiplication tables and rigorously practiced basic mathematical operations through oral methods is much more confident in higher mathematics because he has fewer stumbling blocks to overcome (Narayan, 2009).

Another premise is that rote is about drilling and so direct teaching and extensive practice and drilling (labelled "drill and kill") of algorithms and other standard mathematical procedures is deemed unnecessary and potentially detrimental to children's mathematical development (Geary, 1994; Hirsch, 1996). However,

The argument that drill and practice and the development of basic cognitive skills, such as fact retrieval, are unnecessary and unwanted in mathematics education fails to appreciate the importance of basic skills for mathematics development (Geary, 1994:265).

After analysing a number of neurobiological publications, Hirsch (1996) points out that one finding of neurobiology is that all learning requires repeated efforts (distributed practice), to forge and fix neural networks and that there is no way around repeated and sometimes hard work. Of course, children need to understand mathematical concepts, but they also need automaticity in basic knowledge and skills. Automaticity in basic knowledge and skills means that no or very little conscious effort is needed to use them, and automaticity and thus "real competency only comes from extensive practice" (Anderson, Reder \& Simon, 2000:13). Acting automatically and effortlessly is therefore viewed as acting at the level of mastery. The naïve view is that mathematical competence is directly related to what one "knows" (facts, procedures, conceptual understandings) and that knowledge accumulates to mastery with study and practice (Schoenfeld, 2004).

Another premise is that rote learning only prepares learners for tests and therefore does not promote the development of problem solving skills - so the charge goes. This justification for disparaging rote learning however is not without controversy given the current practice where institutions are more accountable for results than for the mathematical understanding of their students. According to Wright (2012), the high-stakes nature of mathematics assessment makes it difficult to generate quantitative data that provide evidence in support of progressive and critical teaching approaches. Literature shows that teaching (and assessing) through problem solving needs to be further developed and better understood. In the South African research that Brodie \& Pournara (2005), reviewed; this is clearly an area where further research is needed. Meanwhile, mathematics teachers and policy makers in South Africa are under pressure to improve school achievement results, in particular the school-leaving results. In the absence of exemplars of what it might mean to teach and assess using problem solving approaches, Brodie \& Pournara (2005), caution that no matter how inadequate test results may be as a measure of learners' mathematical knowledge, as long as they remain in place, mathematics teachers and educators are obligated to take them seriously because learners' future educational opportunities and career trajectories depend on these results.

\title{
5. Implications for Practice
}

Given that rote learning is a necessary first step in the appropriation of mathematical meaning yet it is disparaged so strongly; I go back to Egan's (2001), question; 'What have we been getting wrong from the beginning?' Egan suggests that in the case of the curriculum what we got wrong was accepting that the important question was 'what knowledge is of most worth' and the catastrophe has followed accepting that a fundamentally problem-solving approach would allow us to answer it. Egan argues that the question should be 'what should constitute an education', and in answering that question it is inadequate to assume an alternative (problem solving) and rebuke its competitor (rote learning) because it doesn't share its conclusions. That simply perpetuates the fruitless and dreary polemics of the current educational discourse (Egan, 2001) and when superficial aspects of reform are implemented without the underlying substance, students may 
not learn much at all. The suggestion that problem solving skills can be achieved without addressing the foundational knowledge is best captured in this metaphor.

Adding wings to caterpillars does not create butterflies -- it creates awkward and dysfunctional caterpillars. Butterflies are created through transformation (Stephanie Pace Marshall, 1995:1).

Indeed the realization that we should go back to the basics comes from observations that we are creating awkward and dysfunctional caterpillars in our learners who end up with neither problem solving skills nor the basics such as addition and multiplication. Schoenfeld (2004) suggests a harmonization of the unwarranted dichotomies set in the math wars, arguing that the polarization which resulted in the 'winner take all' battle between the two extremes back-to-basics movement on one side the problem solving movement on the other was nonsensical. An exclusive focus on basics leaves students without the understandings that enable them to use mathematics effectively. A focus on 'processes' without attention to skill deprives students of the tools they need for fluid, competent performance. The extremes are unattainable and so why have so many people taken extreme positions, and why are things as polarized as they are? More important, what might be done about it?

Schoenfeld (2004) says that finding a resolution is essential because the math wars, like all wars, involve causalities to innocent parties the children who should be well served by mathematics education. He suggests that despite extremist proposals and mandates, there is always a rational middle ground, and many teachers seek it. Narayan (2009) suggested that we develop teaching methodology for mathematics and other subjects that incorporates rote learning in an effective way so that knowledge is better conveyed and represented in the minds of students. Deep understanding of both procedural and conceptual knowledge should be the ultimate goal and priority of all mathematics learning as it refers to an integrated and functional grasp of mathematical ideas.

\section{References}

Anderson, J. R., Reder, L. M. \& Simon, H. A., (2000). Applications and misapplications of cognitive psychology to mathematics education. Texas Educational Review. Available at http://act-r.psy.cmu.edu/papers/misapplied.html (7 August 2013)

Baroody, A. J. \& Wilkins, J. L. M. (1999). The development of informal counting, number, and arithmetic skills and concepts. In J. V. Copley (Ed.,), Mathematics in the early years,(pp. 48-65). National Council of Teachers of Mathematics.

Berger, M. (2006). Making mathematical meaning: from preconcepts, to pseudoconcepts to concepts. Pythagoras, 63, 14 - 21.

Brodie, K. \& Pournara, C. (2005). Towards a framework for developing and researching group work in mathematics classrooms. In R. Vithal, J. Adler \& C. Keitel (Eds.), Researching Mathematics education in South Africa: perspectives, practices and possibilities, (pp. 28 - 72). Cape Town, HSRC Press.

Carnoy, M. Chisholm, L., Chilisa, B., Addy, N., Arends, F., Baloyi, H., et al., (2011). The low achievement trap in middle income countries: comparing Botswana and South Africa. Draft report. Stanford School of Education, Human Sciences Research Council \& University of Botswana.

Department of Basic Education, (2012). Curriculum and Assessment Policy Statement GRADES 4-6 Mathematics, Pretoria, Department of Basic Education.

Egan, K. (2001). Getting it wrong from the beginning: The mismatch between school and children's minds. http://www.educ.sfu.ca/kegan/ Wrong-article.html (7 August 2013)

Egan, K. (2004). Getting it wrong from the beginning: Our progressivist inheritance from Herbert Spencer, John Dewey, and Jean Piaget. New Haven, Yale University Press.

Fleisch, B. (2008). Primary Education in crisis - why South African school children underachieve in reading and mathematics. Cape Town, Juta \& Co, Ltd.

Garner, R. (2011). School curriculum gets back to facts and figures. The Independent 20 January.

Geary, D. C. (2011). Cognitive Predictors of Achievement Growth in Mathematics: A Five year Longitudinal Study. Developmental Psychology; 47(6), $1539-1552$.

Ginsburg, A. Leinwand, S. \& Decker, K. (2009). Informing Grades 1-6 Mathematics Standards Development: What Can Be Learned From High-Performing Hong Kong, Korea and Singapore? American Institute for Research

Gray, E. M. \& Tall, D. O. (1994). Duality, Ambiguity and Flexibility: A Proceptual View of Simple Arithmetic. The Journal for Research in mathematics education, 26(2), $115-141$.

Hiebert, J. \& Lefevre, P. 1986. Conceptual and procedural knowledge in mathematics: An introductory analysis. In J. Hiebert (Ed.), Conceptual and procedural knowledge: The case of mathematics, (pp.1 - 27). Hillsdale, NJ: Erlbaum.

Hirsch, E. D. (2001). Romancing the child. Education next, 1. Available at http://www.hoover.org/publications/ednext/339046.html (7 August 2013)

Horn, I. 2009. Learner-centredness: an analytical critique. South African Journal of Education, 29:511 - 525.

Marshall, S. P. (1995) http://www.21learn.org/publ/systhesis/synthesis_four.htm (7 August, 2013).

Long, C. (2005). Maths concepts in teaching: procedural and conceptual knowledge. Pythagoras, 62, $59-65$.

Narayan, A. (2009). Rote and Algorithmic Techniques in Primary Level Mathematics Teaching in the light of Gagné's Hierarchy. Paper presented at the proceedings of the International Conference to Review Research in Science, technology and Mathematics 
Education, Mumbai.

National Council of Teachers of Mathematics, (2006). Curriculum focal points for pre-kindergarten through grade 8 Mathematics - A quest for coherence. Reston, VA National Council of Teachers of Mathematics.

National Research Council (2009). Mathematics learning in early childhood. Washington, DC: The National Academic Press

Phillips, D. C. (2005). The contested nature of empirical research, Journal of Philosophy of Education, 39(4), $577-597$.

Rips, L. J., Bloomfield, A. \& Asmuth, J. (2008). From numerical concepts to concepts of number. Behavioral and Brain Sciences, 31 , 623- 687.

Schollar, E. (2008). Final report: The primary mathematics research project 2004-2007 - towards evidence-based educational development in South Africa. Johannesburg: Eric Schollar \& Associates.

Schoenfeld, A. (2004). The math wars. Educational Policy, 18(1), $253-286$.

Sfard, A. (1991). On the dual nature of mathematical conceptions: Reflections on processes and objects as different sides of the same coin. Educational studies in Mathematics, 2, 1- 36.

Star, J. R. (2005). Reconceptualising procedural knowledge. Journal for research in Mathematics Education. 30, 171 - 191.

Star, J. R. \& Rittle-Johnson, B. (2009). Making algebra work: Instructional strategies that deepen student understanding, within and between algebraic representations. ERS Spectrum, 27 (2), 11 - 18.

Tall, D. O. (2007). Developing a theory of mathematical growth. ZDM Mathematics Education 39, 145 - 154.

Venkat, H. \& Askew, M. (2012). Mediating early number learning: specialising across teacher talk and tools. Journal of Education, 56:6789.

Vithal, R. \& Volmink, J. (2005). Mathematics curriculum research: roots, reforms, reconciliation and relevance. In R. Vithal, J. Adler \& C. Keitel (Eds.), Researching Mathematics education in South Africa: perspectives, practices and possibilities, (pp. 3 - 27). Cape Town, HSRC Press.

Wilson, W. S. (2009). Elementary school Mathematics priorities. AASA Journal of Scholarship \& Practice, 6(1), 40 - 49.

Wright, P. (2012). The Math Wars: Tensions in the development of school mathematics curricula. For the Learning of Mathematics 32 (2), $7-13$.

Wynn, K. (1992). Children's Acquisition of the Number Words and the Counting System. Cognitive Psychology, 24,220 - 251. 